\title{
Maintaining Competence in General Internal Medicine
}

\author{
Marianne M. Green, M.D
}

Northwestern University Feinberg School of Medicine, Chicago, IL, USA.

J Gen Intern Med 30(7):885

DOI: $10.1007 / \mathrm{s} 11606-015-3347-\mathrm{x}$

() Society of General Internal Medicine 2015

$\mathrm{T}$ o The Editor: As Chair of the American Board of Internal Medicine (ABIM) Internal Medicine Board and former chair of the Internal Medicine Exam Writing Committee, I appreciate Dr. Feldman's recent editorial on the ABIM Maintenance of Certification (MOC) program. ${ }^{1}$ While I cannot comment on specific exam questions due to ABIM's examination non-disclosure policy, I can attest that ABIM exams are carefully constructed by practicing internists and are intended to cover content that the exam committees have determined a qualified candidate should be able to recognize without consulting medical resources or references. Additionally, general internists serve on the Internal Medicine exam committee and collectively decide whether content is appropriate for the practicing internist. All new questions undergo rigorous review by physician experts, followed by pretesting without risk to examinees. More information on ABIM's exam development process is available at http://www.abim.org/about/examInfo/developed.aspx. That said, ABIM agrees with many of the concerns Dr. Feldman raises, which echo what we have heard from other diplomates. Since the editorial's publication, ABIM issued a statement announcing changes to the MOC program in response to diplomate feedback and in recognition that MOC needs to better meet diplomates' needs. ${ }^{2}$ The statement also expresses ABIM's commitment to work closely with diplomates to enhance the MOC program through various channels, including in-person meetings and workshops, diplomate surveys and a blog at http://transforming.abim.org/. Among the announced changes is an update to the Internal Medicine MOC

\footnotetext{
${ }^{1}$ Feldman MD. Maintaining Competence in General Internal Medicine. J Gen Intern Med. 2015 Feb;30(2):143-4.

${ }^{2}$ American Board of Internal Medicine. ABIM Announces Immediate Changes to MOC Program. http://www.abim.org/news/abim-announces-immediate-changes-to-moc-program.aspx. Accessed March 20, 2015.
}

Published online April 28, 2015 examination blueprint to make the exam more reflective of what physicians in practice are doing. Through a structured review process, ABIM is collecting diplomate input on the updated blueprint, which will be implemented for the Fall 2015 MOC exam, with other specialties to follow. Additionally, to make the secure exam a more helpful feedback mechanism to inform physicians' ongoing learning, $\mathrm{ABIM}$ is introducing enhanced exam score reports with the Spring 2015 MOC exam administration. These score reports were developed with feedback from physician focus groups, and will provide exam takers with more detailed exam performance data on their strengths and weaknesses. ABIM also recently launched Assessment 2020, an initiative to work with the broader health care community to define what competencies physicians will need as the field of medicine continues to evolve. The Assessment 2020 website at http://assessment2020.abim. org/ features a blog on which we welcome feedback, as well as a section on exam enhancements in research and development. ${ }^{3}$ As Dr. Feldman noted, all physicians are committed to lifelong learning. MOC needs to be a valueadded process that helps us keep up in our rapidly changing fields and improve the quality of care we provide to our patients. I look forward to working with the community to develop an MOC program that better meets the needs of physicians across the diversity of internal medicine practice.

Conflict of Interest: Dr. Marianne Green is a member of the ABIM Board of Directors, the ABIM Council and of the ABIM Internal Medicine Exam Committee. To protect the integrity of Board Certification, ABIM strictly enforces the confidentiality and its ownership of ABIM exam content, and Dr. Green has agreed to keep ABIM exam content confidential. No ABIM exam content is shared or otherwise disclosed in this article.

Corresponding Author: Marianne M. Green, M.D; Northwestern University Feinberg School of Medicine, Ward 1-003, 303 E. Chicago Ave., Chicago, IL 60611, USA (e-mail: m-green@northwestern.edu).
${ }^{3}$ American Board of Internal Medicine Assessment 2020. Feedback in action. http://assessment2020.abim.org/projects/ Accessed March 20, 2015. 